\title{
Effect of Additives on Hydrophobicity of PVDF Membrane in Two-stage Coagulation Baths for Desalination
}

\author{
Abdul Latif Ahmad, ${ }^{*}$ Mohamad Razif Mohd Ramli and Mohamad Izrin Mohamad Esham \\ School of Chemical Engineering, Universiti Sains Malaysia, \\ Engineering Campus, 14300 Nibong Tebal, Pulau Pinang, Malaysia \\ *Corresponding author: chlatif@usm.my
}

Published online: 25 November 2019

To cite this article: Ahmad, A. L., Mohd Ramli, M. R. \& Mohamad Esham, M. I. (2019). Effect of additives on hydrophobicity of PVDF membrane in two-stage coagulation baths for desalination. J. Phys. Sci., 30(3), 207-221, https://doi.org/10.21315/jps2019.30.3.13

To link to this article: https://doi.org/10.21315/jps2019.30.3.13

\begin{abstract}
This research aimed to improve the hydrophobic polyvinylidene fluoride (PVDF) membrane for direct contact membrane distillation (DCMD) desalination by mixing various additives (dibutyl phthalate and glycerol) in polymer solution via twostage/dual coagulation bath (CB) system. The effect of each additive on the surface and cross-sectional morphology of PVDF membrane was investigated. The addition of additives showed increased in membranes porosity, but the water contact angle was less than $90^{\circ}$ when immersed in single $C B$ (distilled water). Membrane prepared with two-stage $C B$ system immersed into methanol $C B$ for 20 min and transferred into distilled water $C B$ for 24 h exhibited high water contact angle of $114.2^{\circ}, 142.6^{\circ}$ and $120.1^{\circ}$ for membrane $M-3, M-4$ and $M-5$, respectively. The porosity of membrane significantly increased when incorporated with additives. The membrane was further evaluated in DCMD operation for separation performance. The DCMD tested using distilled water and $35 \mathrm{gl}^{-1}$ of sodium chloride ( $\mathrm{NaCl}$ ) aqueous solution in feed showed $\mathrm{M}-4$ achieved the highest flux among other membranes at $13.85 \mathrm{~kg}^{-2} \mathrm{~m}^{-2} \mathrm{~h}^{-1}$ with $99 \%$ salt rejection under $70^{\circ} \mathrm{C}$ of feed temperature.
\end{abstract}

Keywords: Polyvinylidene fluoride, coagulation bath, direct contact membrane distillation, PVDF, desalination

\section{INTRODUCTION}

Membrane technology has become a popular separation technology and has been widely applied for its application in food processing, pharmaceutical industry, drinking water treatment, water purification, desalination of sea and brackish water. ${ }^{1-5}$ Pressure-driven membrane water treatment process such as microfiltration 
(MF), ultrafiltration (UF), nanofiltration (NF) and reverse osmosis (RO) are commonly used to produce clean permeates and remove toxic substances from water bodies. ${ }^{6-8}$ In recent decades, membrane distillation (MD) has been gaining attention as an emerging method for treatment and separation process due to some unique benefits associated with the process. ${ }^{9}$ Figure 1 shows the principle of MD process operated using a hydrophobic membrane to allow only vapour molecule but not bulk water across micro-porous membrane under lower pressure and lower operating temperature compared to RO and distillation, respectively. ${ }^{10}$ Ideally, the MD offers several advantages such as potential $100 \%$ rejection on non-volatile dissolved substances, production of high purity distillate, simplicity in operation, easy to scale up and relatively low energy consumptions. ${ }^{11}$ Direct contact membrane distillation (DCMD), vacuum membrane distillation (VMD), air gap membrane distillation (AGM), and sweep gas membrane distillation (SGMD) are well-known MD configuration process. ${ }^{12-15}$ Among those configurations, DCMD is one of the most common configurations used due to its simplest MD to treat concentrated wastewater. ${ }^{9}$

\section{Hydrophobic Membrane}

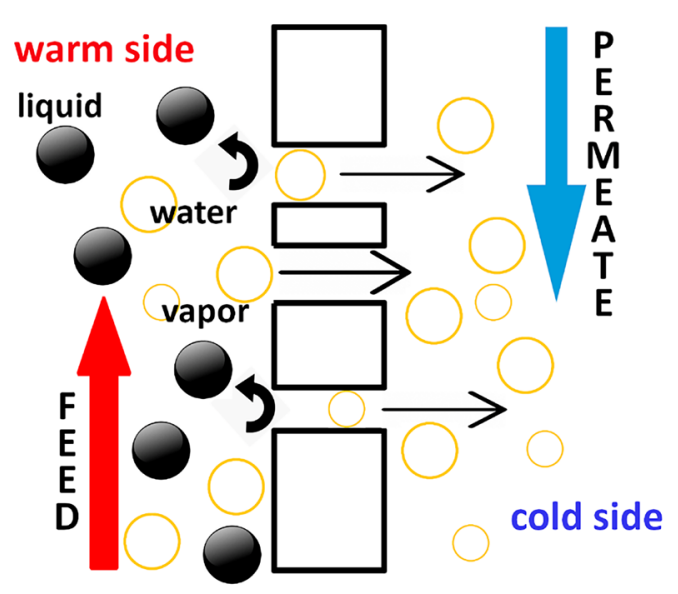

Figure 1: Principle of membrane distillation process.

One of the major hurdles preventing the MD to commercialise in industrial separation technique is the lower permeation flux compared to pressure-driven membrane process due to fouling in water treatment and wetting in the membrane. There are several parameters of the membrane to consider to improve the membrane performances and efficiency such as porosity, tortuosity, chemical resistance, thermal conductivity and quality of distillate product. To meet this condition, 
the membrane for MD must not be wetted by separated aqueous solutions and transports only water vapour across the membrane. Many membrane researchers reported using fluoropolymer membrane due to its hydrophobicity and its excellent processability such as polytetrafluoroethylene (PTFE), polyvinylidene fluoride (PVDF), and PVDF copolymer which are more hydrophobic and present higher solubility including polyvinylidene fluoride-co-hexafluoropropylene (PVDF-coHFP), PTFE-co-hexafluoropropylene(FEP) and PVDF-co-trifluorochloroethylene (PVDF-CTFE) in order to prevent membrane wetting. ${ }^{12,16-19}$ Surface wettability of water contact angle for PVDF-co-HFP was $98.00^{\circ}$, higher compared to PVDF which was $92.19^{\circ}$ due to addition of an amorphous phase of hexafluoropropylene (HFP) into the main constituent vinylidene fluoride (VDF) blocks as reported by Balis et al. ${ }^{20}$

Researchers have proposed several studies to investigate the effect of additive on the properties of PVDF membrane. Zheng et al. used inorganic and organic macromolecule additives such as polyethylene glycol (PEG) and dibutyl phthalate (DBP) for the preparation of PVDF-CTFE membrane and observed that the membrane was found to improve hydrophobicity, relatively small pore and exhibited symmetrical cross-section structure. ${ }^{21}$ Hemmat et al. reported on preparation of PVDF-HFP nanofibre membrane for AGM process and studied the effect of different additives on the morphology and permeation performance of different salt additives (i.e., calcium carbonate or $\mathrm{CaCO}_{3}$, lithium chloride or $\mathrm{LiCl}$ and calcium chloride or $\left.\mathrm{CaCl}_{2}\right) .{ }^{22}$ Higher permeation flux of $9.81 \mathrm{~h}^{-1} \mathrm{~m}^{-2}$, $12.21 \mathrm{~h}^{-1} \mathrm{~m}^{-2}$ and $13.61 \mathrm{~h}^{-1} \mathrm{~m}^{-2}$ were obtained when $\mathrm{CaCO}_{3}, \mathrm{CaCl}_{2}$ and $\mathrm{LiCl}$ were used as an additive, respectively. Similarly, the result found by Khayet. et al show high permeate flux of $53.8 \mathrm{~kg} \mathrm{~m}^{-2} \mathrm{~h}^{-1}$ when polysulfone (PSF) polymer was blended with fluorinated polyurethane additive (FPA) ${ }^{23}$ However, the mechanical strength of the membrane decreased and pore size distribution (PSD) tend to widen when PEG was used as additive as reported by Liu et al. ${ }^{24}$ Thus, fabrication of membrane via two-stage coagulation baths to control PSD typically in the range $0.1-0.5 \mu \mathrm{m}$ with as narrow pore has attracted great attention among researchers. ${ }^{25}$

Thomas et al. introduced two coagulation baths by using deionised (DI) water (first bath) and ethanol (second bath). ${ }^{25}$ The result showed that PSD PVDF $(0.14-0.25 \mu \mathrm{m})$ with a contact angle in the range of $100^{\circ}-127^{\circ}$ was also formed by passing through DI water precipitation within $2-15 \mathrm{~min}$, then immersed into alcohol for $1 \mathrm{~h}$. Similarly, high porosity nearly $89 \%$ with small and narrow PSD when PVDF prepared in two-stage coagulation bath system of $100 \mathrm{wt} \%$ of ethanol and $80 \mathrm{wt} \%$ on NMP in water bath exhibited $127^{\circ} \mathrm{C}$ contact angle. ${ }^{26}$ In this work, hydrophobic PVDF membranes were produced for treatment aquaculture effluent. Distilled water and methanol were used as non-solvent in the coagulation bath to induce the desired co-continuous structure. Besides, forming a porous structure 
with uniform pore size distribution for effective mass transfer, the effect of additives was studied within the polymeric membranes and tested for its impact on water wettability. More importantly, the performance of this hydrophobic membrane was further studied.

\section{EXPERIMENTAL}

\subsection{Materials}

PVDF power (Solef ${ }^{\circledR}$ PVDF) supplied from Solvay Solexis (France) was dried in an oven for $100^{\circ} \mathrm{C}$ for $24 \mathrm{~h}$ to remove its moisture content. N-methyl-2-pyrolidone (NMP) (> 99.5\%) analysis purchased from Merck (Darmstadt, Germany) was used as a solvent. Methanol for analysis acquired from Merck (Darmstadt, Germany) was used as a coagulation bath. The non-solvent additive of the dope solution was dibutyl phthalate (DBP) (>97\%) and glycerol which were supplied by SigmaAldrich (St. Louis., MO, United States). Sodium chloride $(\mathrm{NaCl})$ was bought from Sigma-Aldrich (St. Louis., MO, United States) as the feed solution.

\subsection{Membrane Preparations and Synthesis}

The membrane was synthesised according to literature with some modifications. ${ }^{27}$ The dope solution was prepared by dissolved dried PVDF in NMP in sealed glass flasks under continuously stirred at $700 \mathrm{rpm}$ using magnetic stirrer with the length of $3.5 \mathrm{~cm}$ at $80^{\circ} \mathrm{C}$ for $24 \mathrm{~h}$ and degassed for $1 \mathrm{~h}$. The PVDF solution was then cast on a flat glass plate with a thickness of $500 \mu \mathrm{m}$ at room temperature. After that, the membrane was immersed in distilled water for $24 \mathrm{~h}$. The membrane was removed from the water bath and further dried for 1-2 days to get a dry porous membrane. The above steps were repeated to study the effect of additive and twostage coagulation baths for membrane wettability improvement according to Table 1.

Table 1: The preparation of the PVDF membranes.

\begin{tabular}{lcccccc}
\hline \multirow{2}{*}{ Membrane } & $\begin{array}{c}\text { PVDF } \\
(\mathrm{wt} \%)\end{array}$ & $\begin{array}{c}\text { NMP } \\
(\mathrm{wt} \%)\end{array}$ & $\begin{array}{c}\text { DBP } \\
(\mathrm{wt} \%)\end{array}$ & $\begin{array}{c}\text { Glycerol } \\
(\mathrm{wt} \%)\end{array}$ & \multicolumn{2}{c}{ Coagulation bath (time, t) } \\
\cline { 6 - 7 } & 16 & 84 & - & - & Distilled water (24 h) & - \\
M-0 & 16 & 74 & 10 & - & Distilled water (24 h) & - \\
M-1 & 16 & 74 & - & 10 & Distilled water (24 h) & - \\
M-2 & 16 & 84 & - & - & Methanol (20 min) & Distilled water (24 h) \\
M-3 & 16 & 74 & 10 & - & Methanol (20 min $)$ & Distilled water (24 h) \\
M-4 & 16 & 74 & - & 10 & Methanol (20 min $)$ & Distilled water (24 h) \\
M-5 & & & & & & \\
\hline
\end{tabular}




\subsection{Membrane Characterisation}

\subsubsection{Surface and cross-sectional morphology checking}

For morphology observation, the membranes were examined by scanning electron microscopy (SEM) using Hitachi TM-3000 TableTop. For cross-sectional morphology, the flat sheet membrane was immersed inside liquid nitrogen then cracked to obtain a brittle and clean fracture. ${ }^{28}$ The membrane samples were coated with conducting layer of gold and finally observed using SEM.

\subsubsection{Membrane porosity}

For porosity measurement, the membrane was immersed in 2-butanol (Merck) solution for $2 \mathrm{~h}$ to ensure all the pores will be filled with the liquid and after drying, the porosity of membrane was calculated by the following equation: ${ }^{25}$

$$
\varepsilon=\frac{\frac{m_{n}}{\rho_{n}}}{\frac{m_{n}}{\rho_{n}}+\frac{m_{p}}{\rho_{p}}} \times 100 \%
$$

where $\varepsilon$ indicates the porosity of membrane; $m_{p}$ and $m_{n}$ are the mass of the dry and wetted membranes, respectively; and $\rho_{p}$ and $\rho_{n}$ are the density of the PVDF $\left(1.78 \mathrm{~g} \mathrm{~cm}^{-3}\right)$ and density of butanol $\left(0.81 \mathrm{~g} \mathrm{~cm}^{-3}\right)$, respectively. The calculation of porosity was taken with five measurements and averaged to reduce error. ${ }^{26}$

\subsubsection{Pore size and liquid entry pressure}

The pore size of membranes was analysed using Capillary Flow Porometer (Porolux 1000, Belgium) by following "dry up-wet up" method. The pressure of gas was gradually increased from 1 to 5 bar and the gas flow rate was recorded. Bubble point was recorded when the pressure was high enough to remove the liquid out from the largest pores. As pressure was gradually increased, smaller pores become unblocked by liquid and the gas flow rate increased until the whole sample completely dry. The cumulative pressure was used to calculate pore size distribution and average pore size. The pore sizes were estimated using perfluorether (porefil) solution whereas liquid entry pressure $\left(\mathrm{LEP}_{\mathrm{w}}\right)$ were measured from wet PVDF membrane using PMI software. ${ }^{29}$ 


\subsubsection{Contact angle}

The membrane wettability or water contact angle (CA) on the membrane was evaluated via the static CA of membrane samples using a goniometer (Rame'Hart Instrument Co., United States) based on sessile drop method. DI water was dropped through micro syringe onto the smooth surface of the membrane under room temperature. Then, a microscope was used to capture the micrographs. This step was repeated for five different spots of the membrane sample to calculate the average and reduce the random error.

\subsection{Membrane distillation experiment}

In this experiment, DCMD as shown in Figure 2 was used to evaluate the performance of PVDF membrane. The membrane module was fixed in two chambers connected horizontally through the experiment for $42 \mathrm{~cm}^{2}$ of membrane area. The feed consists $35 \mathrm{~g} \mathrm{l}^{-1}$ sodium chloride heated at $70^{\circ} \mathrm{C}$ by placing it in hot water bath (Protech $\mathrm{HC}-10$ ) and permeate side of distilled water at $20^{\circ} \mathrm{C}$ were circulated counter-currently with flowrate $8 \mathrm{GPH}$ with two peristaltic pumps (Master-Flex). A stopwatch was used to record the time interval for mass reading at $1 \mathrm{~min}$. Each of the membrane sheets was circulated with distilled water before using sodium chloride as a feed solution. The permeate flux $\left(\mathrm{kg} \mathrm{m}^{-2} \mathrm{~h}^{-1}\right)$ of the membrane through MD was calculated according to the following equation:

$$
J=\frac{\Delta W}{A \Delta t}
$$

where $J$ is the permeate flux $\left(\mathrm{kg} \mathrm{m}^{-2} \mathrm{~h}^{-1}\right), \Delta W$ is quantity of mass distillate $(\mathrm{kg})$, $A$ is the flat-sheet surface area of the porous membrane $\left(\mathrm{m}^{2}\right)$ and $\Delta t$ is the sampling time (h). The rejection coefficient $\mathrm{R}$, was calculated by the following equation:

$$
\mathrm{R}(\%)=\left[1-\frac{C_{p}}{C_{f}}\right] \times 100
$$

where $C_{f}$ is the concentration of the feed $\left(\mathrm{kg} \mathrm{l}^{-1}\right)$ and $C_{p}$ is the concentration of permeate $\left(\mathrm{kg} \mathrm{l}^{-1}\right)$. The concentration was calculated based on the total nutrients of samples measured as previously. 


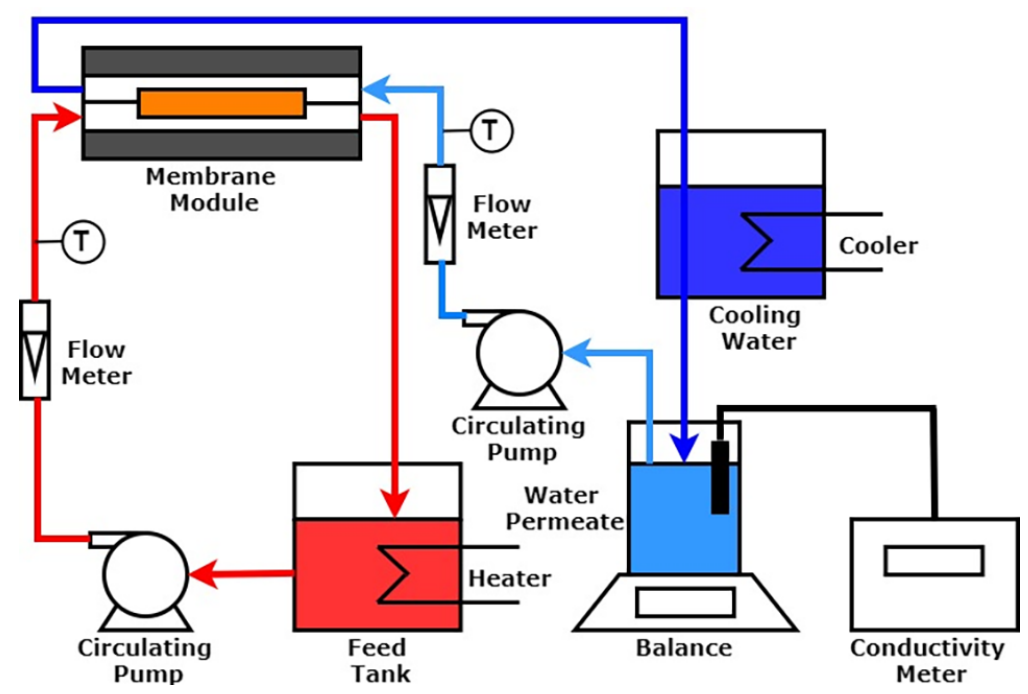

Figure 2: Schematic diagram of DCMD.

\section{RESULTS AND DISCUSSION}

\subsection{Characterisation of Membranes}

\subsubsection{Effect of additives using a single CB}

Membrane with different additives (glycerol, DBP) was synthesised using a single $\mathrm{CB}$ and its physicochemical properties were examined. Figure 3(a and b) shows the SEM images (surface and cross-section) and contact angle of the PVDF of a pristine membrane (without additive), 10\% of glycerol and 10\% of DBP denoted as $\mathrm{M}-0, \mathrm{M}-1, \mathrm{M}-2$ respectively. For pristine $\mathrm{M}-0$ membrane prepared with NMP as solvent undergo fast solidification of the surface layer due to rapid L-L demixing process with low surface hydrophobicity of $63.6^{\circ}$ and thick skin layer. On the other hand, dope solution incorporated with DBP as non-solvent additives would delay S-L demixing where water diffused slowly in polymer solution and as a result formed smaller pore with dense skin and obtained water contact angle of $75.6^{\circ}$. The membrane fabricated containing glycerol exhibited similar result as DBP on the membrane properties with a second-highest contact angle of $74.6^{\circ}$. It can be observed from the top surface of the membrane a clear distribution of pore exists in M-1(a) followed by M-2(a) and M-0(a), respectively and some regions of the membrane show a very open structure. The cross-sectional of membrane M-0(b) and M-2(b) shows an array of finger-like structure and M-1(b) shows macro voids which can affect the mechanical strength of the membrane. 

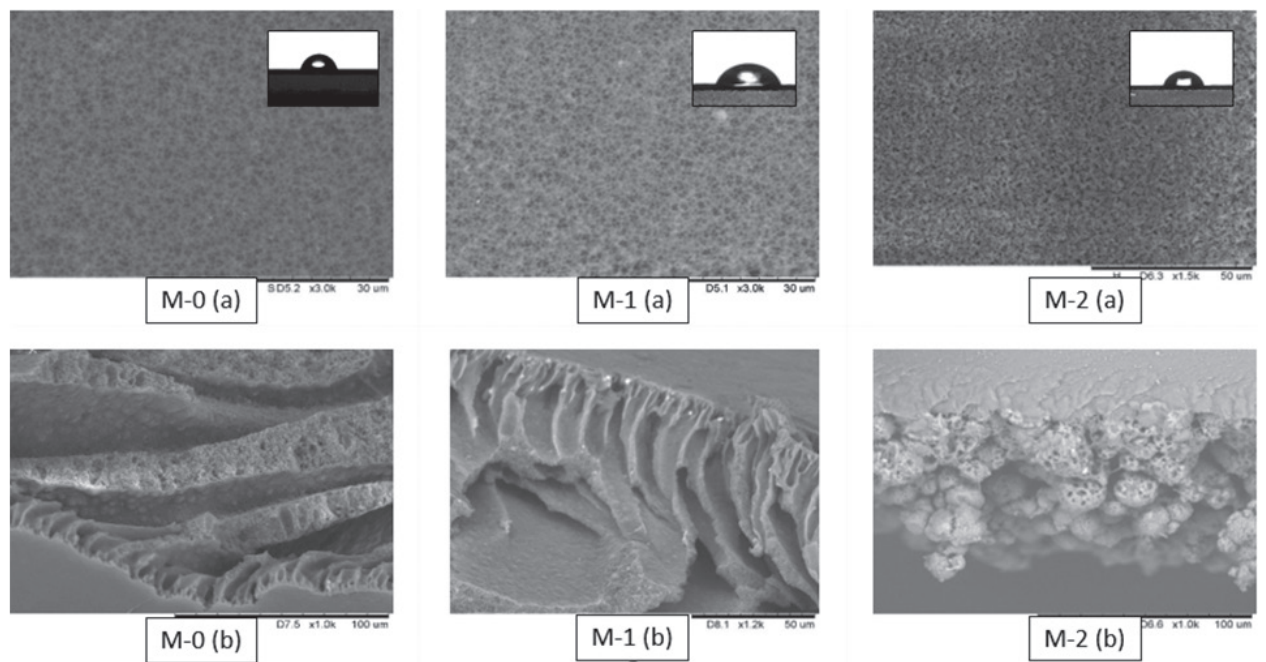

Figure 3: SEM configurations (surface and cross-sectional) and contact angle of PVDF in single CB.

\subsubsection{Enhancement of hydrophobicity in the dual CB system}

PVDF membrane prepared in dual CB system denoted as M-3, M-4 and M-5 were analysed to understand the effect on morphology and hydrophobicity of membrane. Methanol was chosen as first non-solvent $\mathrm{CB}$ and transferred to distilled water (two-stage CB technique). As seen in Figure 4, the surface of PVDF membrane changed from asymmetric structure with finger-like void (single $\mathrm{CB}$ ) to symmetric structure packed with spherical particles and diminishing macro voids was obtained due to impact of first CB. M-3 consists of the bigger nodule and spherical whereas M-4 and M-5 consist of smaller and linked nodular structure. Meanwhile, the employment of methanol in CB may induce delayed liquid-liquid demixing of polymer exhibiting much thicker interconnected structure. While cross-sectional morphologies showed not much difference, the structure became more compact with the addition of additives due to the presence of DBP and glycerol for M-4 and M-5, respectively. Surface hydrophobicity, one of the important parameters, was measured which was represented by the contact angle of the water droplet on the surface of PVDF membrane. In general, membrane hydrophobicity is reflected by a higher contact angle for MD operation to create an air gap and reduce pore wetting on the membrane surface. ${ }^{29}$ 

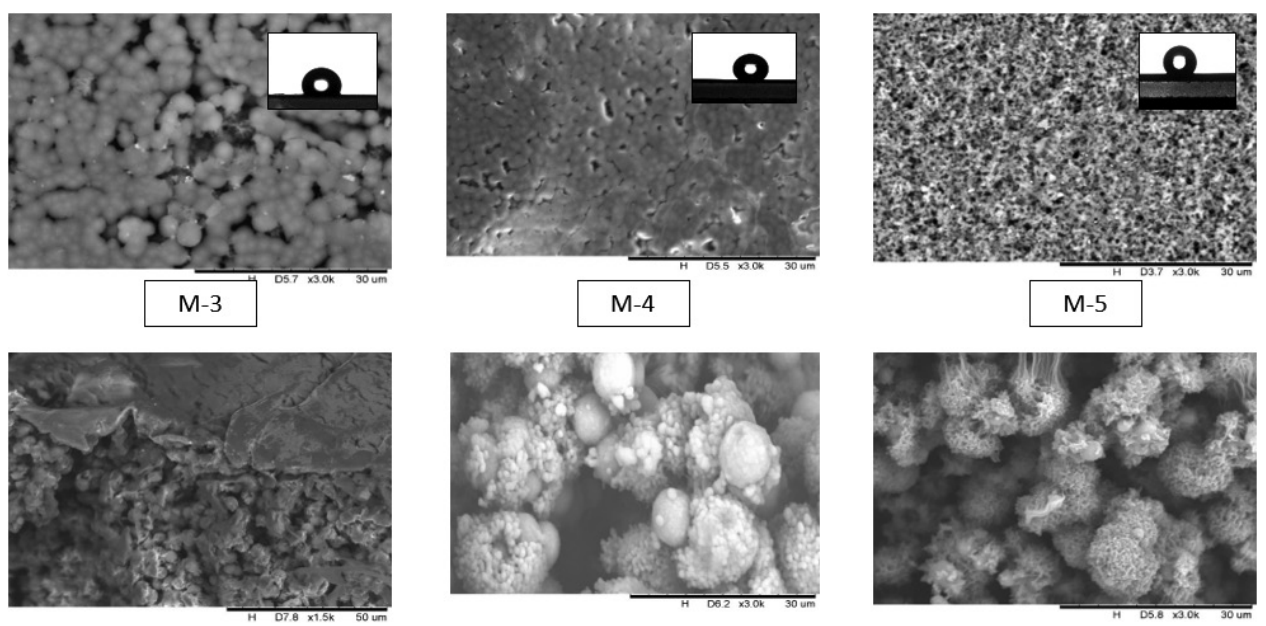

Figure 4: SEM configurations and water contact angle droplet for dual CB system.

Surface hydrophobicity can be enhanced by in phase inversion method (dual coagulation bath method) exhibiting hydrophobic characteristics with a higher contact angle. ${ }^{30}$ It should be noted that membrane immersed in softer precipitation such as ethanol, methanol, octanol, etc., prevents the asymmetric structure which leads to improving the wettability of membrane. The droplet images can be seen in Figure 4 for M-3, M-4, M-5 and the values were listed in Table 3 indicating that all PVDF membranes prepared by dual CB resulted in the hydrophobic membrane. For M-3 and M-5 the contact angle values fall in the range of $114.2^{\circ}-120.1^{\circ}$ which corresponded to improved hydrophobicity of the membrane compared to the membrane immersed in single $\mathrm{CB}$, whereas M-4 achieved superhydrophobic membrane with water contact angle $142.6^{\circ}$. Based on Table 3 , it seems that the membrane with a higher porosity gave a higher contact angle. Methanol, a weak non-solvent for PVDF acting as second CB, played an important role in profiling the pore size and porosity of membrane due to combined effects of macro-voids diminishing and variety of pore size distribution which can reduce the rate of polymer precipitations. M-0, M-1 and M-2 possessed the lowest porosity among all the samples due to its rapid L-L demixing rate when immersed in single CB (distilled water) because water acts as strong non-solvent. Furthermore, these low porosities of the membrane are excluded from consideration for MD operation because membrane porosity with improved hydrophobicity is expected to contribute to higher mass transfer rate in MD performance. Besides, M-4 demonstrated the highest porosity due to its spherulitic crystal structures affected by phase inversion method and resulted in much slower L-L demixing. This is because of the lower concentration gradients between the membrane and $\mathrm{CB}$ which impeded the 
exchange process. On the other side, the addition of glycerol on polymer solution improved the porosity because of its continuous and open-pore structure. This phenomenon can be explained based on the concept of $\mathrm{LEP}_{\mathrm{w}}$ increment. ${ }^{31}$ For the MD process, $\mathrm{LEP}_{\mathrm{w}}$ should be high enough to prevent wetting of membrane pores. This characteristic may be achieved by using membrane material with high hydrophobicity and maximum pore size. Generally, we observed that the $\operatorname{LEP}_{\mathrm{w}}$ of the membrane M-0, M-1 and M-2 are low making their wetting during MD operation likely. Only M-4 membrane was recorded having high $\mathrm{LEP}_{\mathrm{w}}$ which indicates that wetting phenomenon could be reduced. However, not all membranes in Table 3 meet a criterion for MD application because of the low contact angle and $\mathrm{LEP}_{\mathrm{w}}$ values resulted in wetting. Only a few membranes with optimum contact angle, porosity and $\mathrm{LEP}_{\mathrm{w}}$ are fit in MD in operation.

Table 2: The characteristics of the PVDF membranes.

\begin{tabular}{lcccc}
\hline Membrane & $\begin{array}{c}\text { Water contact angle } \\
\left({ }^{\circ}\right)\end{array}$ & $\begin{array}{c}\text { Mean pore size } \\
(\mu \mathrm{m})\end{array}$ & $\begin{array}{c}\text { Porosity } \\
(\%)\end{array}$ & $\begin{array}{c}\mathrm{LEP}_{\mathrm{w}} \\
(\mathrm{bar})\end{array}$ \\
\hline M-0 & 63.60 & 0.37 & 30.30 & $0.57 \pm 0.02$ \\
M-1 & 74.60 & 0.40 & 49.90 & $0.67 \pm 0.03$ \\
M-2 & 75.40 & 0.44 & 58.50 & $0.60 \pm 0.02$ \\
M-3 & 114.20 & 0.28 & 79.40 & $0.66 \pm 0.01$ \\
M-4 & 142.60 & 0.32 & 83.40 & $0.84 \pm 0.02$ \\
M-5 & 120.10 & 0.29 & 81.40 & $0.78 \pm 0.03$ \\
\hline
\end{tabular}

\subsection{DCMD Flux Performance}

\subsubsection{Comparison of MD performance for synthesised membranes}

Based on characterisation test results in term of surface morphology, wettability, porosity and $\mathrm{LEP}_{\mathrm{w}}$ of the membrane, it was concluded that three membranes, i.e., M-3, M-4 and M-5, had the highest potential for practical application in MD and achieved a great rejection of salt which is more than $99 \%$ (Figure 5) with various permeation flux as they own different morphologies. The hydrophobic surface of membranes was enough to prevent salt solution from passing through the microporous PVDF membrane. However, the significant difference in pore size, porosity and hydrophobicity of membrane affected the flux for the feed containing water or salt solution. Among above membranes, M-4 shows the highest permeate flux at $70^{\circ} \mathrm{C}$ and $6 \mathrm{GPH}$ was $13.85 \mathrm{~kg} \mathrm{~m}^{-2} \mathrm{~h}^{-1}$ because of non-wetted membrane surface and relatively high porosity which exerts minimum flow resistance to the vapour. These two criterions are important to promote better mass transfer and prevent liquid filling the pore of the membrane which can lead to fouling and 


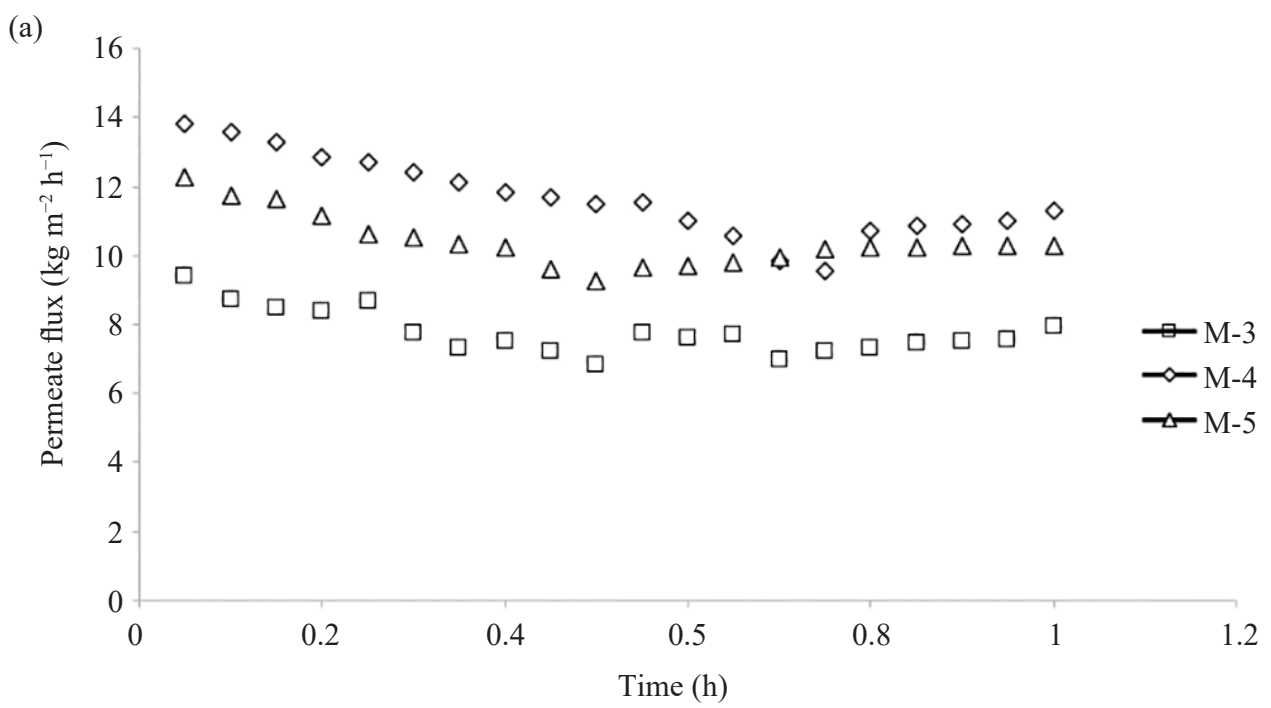

(b)

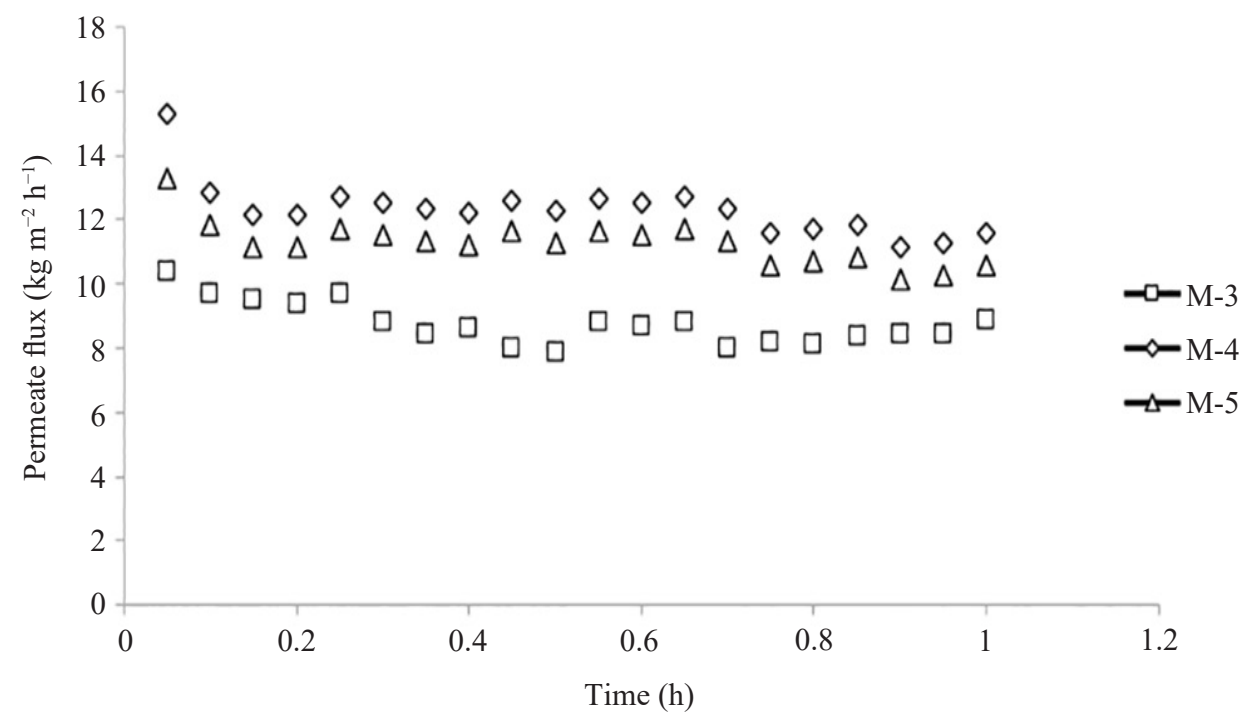

Figure 5: Permeation flux in (a) DCMD for the salt solution, and (b) DCMD of distilled water. 
reduction in the permeate flux as reported by others. ${ }^{32} \mathrm{M}-3$ membrane exhibited the lowest permeate flux for desalination process estimated to be around 9.42 $\mathrm{kg} \mathrm{m}^{-2} \mathrm{~h}^{-1}$ at the same temperature due to low membrane porosity $(79.4 \%)$ and its potential to have pore wetting phenomenon. Therefore, the efficiency of the driving force could reduce and gave higher water permeation resistance. On the other hand, the M-5 has the second-highest flux which was $12.28 \mathrm{~kg} \mathrm{~m}^{-2} \mathrm{~h}^{-1}$ under same conditions after M-4. The value of flux decreased from M-4 to M-5 showing the hydrophobic membrane with a contact angle of $120.1^{\circ} \mathrm{C}$ and $\mathrm{LEP}_{w}$ of $0.78 \mathrm{bar}$ not sufficient enough to promote substantial resistance to membrane wetting. It can be seen that the flux for feed containing distilled water are highest at $10.42 \mathrm{~kg}$ $\mathrm{m}^{-2} \mathrm{~h}^{-1} 13.28 \mathrm{~kg} \mathrm{~m}^{-2} \mathrm{~h}^{-1}$ and $15.28 \mathrm{~kg} \mathrm{~m}^{-2} \mathrm{~h}^{-1}$ for M-3, M-5 and M-4, respectively, compared to the flux of salt solution. This difference in separation performance indicate that an increase in the concentration of the solution in feed could affect the permeation flux of membrane.

\section{CONCLUSION}

In this study, the hydrophobic membrane was successfully synthesised via twostage $\mathrm{CB}$ with various additives. It was found that additives play an important role in changing membrane's physical and chemical properties which lead to slower L-L demixing as a result of increase in membrane porosity. Two-stage CB enhanced membrane hydrophobicity with highest water contact angle $142.6^{\circ}$ for M-4 without giving many effects on porosity, pore size and LEP ${ }_{w}$ of the membrane. The three membranes denoted as M-3, M-4 and M-5 were suitable candidates for MD applications. The optimum membrane tested using distilled water and salt solution as feed for DCMD operation. The permeation flux using distilled water was higher ranging $10.42 \mathrm{~kg} \mathrm{~m}^{-2} \mathrm{~h}^{-1}-15.28 \mathrm{~kg} \mathrm{~m}^{-2} \mathrm{~h}^{-1}$ compared to the salt solution in between $9.42 \mathrm{~kg} \mathrm{~m}^{-2} \mathrm{~h}^{-1}$ and was $13.85 \mathrm{~kg} \mathrm{~m}^{-2} \mathrm{~h}^{-1}$ for temperature $70^{\circ} \mathrm{C}$.

\section{ACKNOWLEDGEMENTS}

The authors acknowledge the financial support to Mohamad Razif Mohd Ramli by Universiti Sains Malaysia under the fellowship scheme. The authors would also like to acknowledge the Ministry of Education Malaysia for the Trans-disciplinary Research Grant Scheme (TRGS) grant (203.PJKIMIA.67612001). 


\section{REFERENCES}

1. Jeong, Y., Hermanowicz, S. W. \& Park, C. (2017). Treatment of food waste recycling wastewater using anaerobic ceramic membrane bioreactor for biogas production in the mainstream treatment process of domestic wastewater. Water Res., 123, 86-95.

2. Farahani, M. H. D. A. \& Chung, T. S. (2018). Solvent resistant hollow fibre membranes comprising P84 polyimide and amine-functionalized carbon nanotubes with potential applications in pharmaceutical, food, and petrochemical industries. Chem. Eng. J., 345, 174-185.

3. Li, W. et al. (2019). Effective removal of fluorescent microparticles as Cryptosporidium parvum surrogates in drinking water treatment by the metallic membrane. J. Memb. Sci., 594, 117434.

4. Han, X. et al. (2019). Bio-derived ultrathin membrane for solar-driven water purification. Nano Energy, 60, 567-575.

5. Guo, J. et al. (2019). Regeneration of superhydrophobic $\mathrm{TiO}_{2}$ electrospun membranes in seawater desalination by water flushing in membrane distillation. Desalin., 468, 114054.

6. Arévalo, J. et al. (2009). Wastewater reuse after treatment by tertiary ultrafiltration and a membrane bioreactor (MBR): A comparative study. Desalin., 243(1-3), $32-41$.

7. Zhang, X. et al. (2019). Nanofiltration membranes with hydrophobic microfiltration substrates for robust structure stability and high water permeation flux. J. Membr. Sci., 593, 117444.

8. Lilane, A. et al. (2019). Modeling and simulation of the performances of the reverse osmosis membrane. Mater. Today Proc., https://doi.org/10.1016/j. matpr.2019.07.694.

9. Drioli, E. et al. (2015). Membrane distillation: Recent developments and perspectives. DES, 356, 56-84.

10. Hamzah, N. \& Leo, C. P. (2017). Membrane distillation of saline with phenolic compound using superhydrophobic PVDF membrane incorporated with $\mathrm{TiO}_{2}$ nanoparticles: Separation, fouling and self-cleaning evaluation. Desalin., 418, 79-88.

11. Zhang, P. et al. (2015). Scale reduction and cleaning techniques during direct contact membrane distillation of seawater reverse osmosis brine. Desalin., 374, 20-30.

12. Hou, D. et al. (2012). Preparation and properties of PVDF composite hollow fiber membranes for desalination through direct contact membrane distillation. J. Membr. Sci., 405-406, 185-200.

13. Zhao, Z.-P. et al. (2008). Concentration of ginseng extracts aqueous solution by vacuum membrane distillation. 1: Effects of operating conditions. Desalin., 234(1), 152-157.

14. Singh, D. \& Sirkar, K. K. (2012). Desalination by air gap membrane distillation using a two hollow-fiber-set membrane module. J. Membr. Sci., 421-422, 172-179. 
15. Khayet, M., Godino, M. P. \& Mengual, J. I. (2003). Theoretical and experimental studies on desalination using the sweeping gas membrane distillation method. Desalin., 157(1), 297-305.

16. Li, K. et al. (2018). Optimizing stretching conditions in fabrication of PTFE hollow fiber membrane for performance improvement in membrane distillation. J. Membr. Sci., 550, 126-135.

17. García-Payo, M. C., Essalhi, M. \& Khayet, M. (2010). Effects of PVDF-HFP concentration on membrane distillation performance and structural morphology of hollow fiber membranes. J. Membr. Sci., 347(1-2), 209-219.

18. Chen, K. et al. (2015). Study on vacuum membrane distillation (VMD) using FEP hollow fiber membrane. Desalin., 375, 24-32.

19. Wang, J. et al. (2016). Fabrication of hydrophobic flat sheet and hollow fiber membranes from PVDF and PVDF-CTFE for membrane distillation. J. Membr. Sci., 497, 183-193.

20. Balis, E. et al. (2018). Enhancement of vapor flux and salt rejection efficiency induced by low cost-high purity MWCNTs in upscaled PVDF and PVDF-HFP hollow fiber modules for membrane distillation. Sep. Purif. Technol., 224, 163-179.

21. Zheng, L. et al. (2016). Effect of non-solvent additives on the morphology, pore structure, and direct contact membrane distillation performance of PVDF-CTFE hydrophobic membranes. J. Environ. Sci., 45, 28-39.

22. Hemmat, A. et al. (2015). Effect of salt additives on the fabrication of poly (vinylidene fluoride-co-hexafluropropylene) (PVDF-HFP) nanofiber membranes for air gap membrane distillation. Proced. Mater. Sci., 11, 370-375.

23. Khayet, M. et al. (2019). Superhydrophobic nanofibers electrospun by surface segregating fluorinated amphiphilic additive for membrane distillation. J. Membr. Sci., 588, 117215.

24. Liu, F. et al. (2011). Progress in the production and modification of PVDF membranes. J. Membr. Sci., 375(1-2), 1-27.

25. Thomas, R. et al. (2014). Pore structure control of PVDF membranes using a 2-stage coagulation bath phase inversion process for application in membrane distillation (MD). J. Membr. Sci., 452, 470-480.

26. Ahmad, A. L. \& Ramli, W. K. W. (2013). Hydrophobic PVDF membrane via twostage soft coagulation bath system for membrane gas absorption of $\mathrm{CO}_{2}$. Sep. Purif. Technol., 103, 230-240.

27. Ahmad, A. L., Shoparwe, N. F. \& Hanifa, N. H. E. (2019). Equilibrium and kinetic study of bovine serum albumin (BSA) adsorption onto fabricated polyethersulfone (PES)/hydroxyapatite (HAP) adsorptive mixed matrix membrane (MMM). J. Phys. Sci., 30(Supp. 1), 43-63, https://doi.org/10.21315/jps2019.30.s1.3.

28. Ngang, H. P. et al. (2012). Preparation of $\mathrm{PVDF}-\mathrm{TiO}_{2}$ mixed-matrix membrane and its evaluation on dye adsorption and UV-cleaning properties. Chem. Eng. J., 197, 359-367.

29. Ahmad, A. L. et al. (2011). Morphology and polymorph study of a polyvinylidene fluoride (PVDF) membrane for protein binding: Effect of the dissolving temperature. Desalin., 278(1), 318-324. 
30. Liu, Y. et al. (2018). Fabrication of novel Janus membrane by nonsolvent thermally induced phase separation (NTIPS) for enhanced performance in membrane distillation. J. Membr. Sci., 563, 298-308.

31. Venault, A. et al. (2013). A review on polymeric membranes and hydrogels prepared by vapor-induced phase separation process. Polym. Rev., 53(4), 568-626.

32. Dong, Z.-Q. et al. (2015). Superhydrophobic modification of PVDF-SiO2 electrospun nanofiber membranes for vacuum membrane distillation. RSC $A d v$., 5(83), 67962-67970. 